\title{
Análise ergonômica da operação de rebitagem em panelas de alumínio
}

O presente estudo analisou as condições ergonômicas de um posto de trabalho de rebitagem em panelas de alumínio em uma fábrica de utensílios domésticos no município de Juazeiro do Norte (CE). É um estudo de caso de caráter qualitativo, exploratório e explicativo. A pesquisa de campo foi desenvolvida com base na Norma Regulamentadora no17 (NR-17), e se apoiou em visitas técnicas e entrevistas com a operária do setor de rebitagem e o encarregado de produção. Os resultados revelaram condições térmicas e lumínicas inadequadas, além de ritmo excessivo de trabalho e desconforto no assento. As principais propostas de intervenções são: instalação de luminárias com maior eficiência e sistema de ventilação e resfriamento evaporativo para diferentes características térmicas do ano, combinado a ampliação das aberturas das janelas; inserção de pausas para aliviar o ritmo de trabalho; e aquisição de uma cadeira adaptada às características da operária.

Palavras-chave: Ergonomia; Panelas de Alumínio; Rebitagem.

\section{Ergonomic analysis of aluminum pan riveting operation}

The present study analyzed the ergonomic conditions of an aluminum pot riveting workstation in a household utensils factory in Juazeiro do Norte (CE). It is a qualitative, exploratory and explanatory case study. The field research was developed based on Regulatory Standard No. 17 (NR-17), and was based on technical visits and interviews with the riveting worker and the production manager. Results revealed inadequate thermal and lumen conditions, excessive work rate and seat discomfort. The main proposals for interventions are: installation of more efficient luminaires and evaporative cooling and ventilation system for different thermal characteristics of the year, combined with the widening of window openings; insertion of breaks to relieve the work pace; and acquisition of a chair adapted to the characteristics of the worker.

Keywords: Ergonomics; Aluminum cookware; Riveting.

Topic: Engenharia do Trabalho

Reviewed anonymously in the process of blind peer.
Received: 07/01/2019

Approved: 08/03/2019
Thays Lorranny da Silva Januário (iD) Universidade Regional do Cariri, Brasil http://lattes.cnpq.br/1451698935293740 http://orcid.org/0000-0002-0682-7629 eng.thays@hotmail.com

José Gonçalves de Araújo Filho

Universidade Regional do Cariri, Brasil http://lattes.cnpq.br/4909589002760742 araujo.filho@urca.br

Esdras Alex Freire de Oliveira (D)

Universidade Federal de Lavras, Brasil

http://lattes.cnpq.br/5691436224279198

http://orcid.org/0000-0002-2473-5728

esdras-alex@hotmail.com
Referencing this:

JANUÁRIO, T. L. S.; ARAUJO FILHO, J. G.; OLIVEIRA, E. A. F.. Análise ergonômica da operação de rebitagem em panelas de alumínio. Revista Brasileira de Administração Científica, v.10, n.1, p.69-76, 2019. DOI: http://doi.org/10.6008/CBPC2179-684X.2019.001.0006 


\section{INTRODUÇÃO}

O mercado brasileiro de utensílios domésticos juntamente com os aparelhos eletrônicos representou cerca de 70\% das vendas efetivadas no ano de 2015 (CDL, 2016). No Ceará o setor eletro-metalmecânico é heterogêneo e é responsável por 2,6\% da indústria cearense, estando presente em 72 municípios, o que representa alcance de quase $40 \%$ do território do estado. Na capital do estado, o setor gera quase 65 mil empregos diretos em 1.227 estabelecimentos (FIEC, 2015).

A região do Cariri cearense possui 130 fábricas de panelas de alumínio formalizadas e mais 70 informais, levando a região ao nível de 4o polo industrial de alumínio do Brasil e o primeiro do Nordeste, na produção de panelas. Hoje o setor chega a gerar R\$144mi por ano, nas três principais cidades do cariri. Juazeiro do Norte assume a hegemonia desse montante, com cerca de R\$ $96 \mathrm{mi}$. São cerca de 4 mil empregos formais e mais de 10.000 indiretos (SIMEC, 2017; SANTOS, 2016).

Alças, encaixes, puxadores e cabos estão presentes em praticamente todas as panelas. São peças confeccionadas em materiais isolantes e fixadas às bordas da panela ou tampa para evitar queimar as mãos do usuário devido à transferência de calor pelo contato com a base aquecida desse utensílio. No processo de fixação, a rebitagem mecânica apresenta vantagens, principalmente quando é usada a rebitadeira pneumática ou hidráulica. São máquinas que operam com rapidez e permite rebitamento mais resistente, pois o rebite preenche totalmente o furo, sem deixar espaço.

$\mathrm{Na}$ operação de rebitagem, o operador está condicionado a vários fatores de riscos ergonômicos. Diagnosticar quais os procedimentos e ações presentes no processo produtivo torna possível avaliar conjuntamente aspectos como: a duração da jornada de trabalho, a função, o ciclo da tarefa, o número de movimentos, as pausas, as exigências posturais, o esforço muscular e ritmo necessário para a realização da tarefa, assim como os tipos de ferramentas, os equipamentos e as condições globais de trabalho.

Desse modo, a análise ergonômica pode contribuir para a melhoria das situações de trabalho (GUARES, 2016). Objetivou-se, com este trabalho, analisar ergonomicamente o setor fabril de rebitagem de panelas de alumínio, localizada em Juazeiro do Norte (CE), a fim de propor melhorias ergonômicas que trarão melhores condições de trabalho e qualidade de vida à funcionária do serviço de rebitagem.

\section{REFERENCIAL TEÓRICO}

O objetivo da Ergonomia é 'adaptar o trabalho ao homem ou à mulher' e não 'adaptar o homem ou a mulher ao trabalho', para isso deve-se conhecer os limites e características psicofisiológicas dos humanos para transformar o trabalho. Portanto, não se contenta em compreender o trabalho. Os conhecimentos que ela mobiliza, ou revela, têm em vista a ação, a transformação desta situação de trabalho. A Ergonomia busca então analisar a atividade de trabalho no contexto onde ela é realizada, adequando às características fisiológicas e psicológicas do trabalhador visando o conforto, a segurança e eficiência (BELLO et al., 2016; DANIELLOU et al., 2007; WISNER, 2004). 
No Brasil, a Norma Regulamentadora no17 (NR-17) estabelece parâmetros que visam permitir a adaptação das condições de trabalho disponibilizadas pela empresa às características dos funcionários com o propósito de oferecer mais conforto, segurança e melhora no desempenho das atividades, com o objetivo de atender diferentes necessidades do trabalhador, em diversos campos de atuação (PAULA et al., 2016; PEDROSA et al., 2016).

As condições ambientais desfavoráveis como excesso de calor, ruído e vibrações, assim como a deficiência de iluminação, são fontes de tensão no trabalho que acabam por causar desconforto, aumentar o risco de acidentes e podem provocar danos consideráveis à saúde dos trabalhadores (IIDA, 1990; GRANDJEAN, 1998). Por outro lado, as afecções caracterizadas como Lesões por Esforços Repetitivos (LER) ou Disfunções Osteomusculares Relacionados ao Trabalho (DORT) podem comprometer gravemente a capacidade laboral, correspondendo a um conjunto de desordens inflamatórias e/ou degenerativas que acometem tendões, nervos, músculos, articulações, e resultam principalmente em dor e incapacidade funcional, sendo um motivo de preocupação em todo o mundo (LONG et al., 2012; MERLO et al., 2003).

As LER/DORT, especialmente as que atingem os membros superiores, vêm apresentando prevalência crescente nas sociedades ocidentais e sua ocorrência alcança 50 a $80 \%$ da população economicamente ativa. Esses distúrbios/doenças do sistema musculoesquelético podem ser provocados devido a algumas condições do ambiente de trabalho, como movimentos repetitivos, aplicação de forças, principalmente com as mãos, levantamento e transporte de pesos, posturas inadequadas e stress, referentes às condições psicossociais onde o trabalho acontece (BLYTH et al., 2001; MUGGLETON et al., 1999)

O aparecimento das afecções está ligado à exposição dos trabalhadores a esses riscos e sua magnitude depende da intensidade, frequência e duração da exposição, e da capacidade individual de lidar com as exigências do trabalho (BACKABERG et al., 2014; JELLAD et al., 2013; MARTINS, 2011). As LER/DORT, em geral, associam-se à ergonomia inadequada no processo de trabalho, e resultam de problemas relacionados diretamente ao local de trabalho, inadequação do mobiliário, das ferramentas e instrumentos; e/ou fatores relacionados ao trabalhador, como postura inadequada e apreensão de instrumentos de modo não ergonômico (PICOLOTO et al., 2008; FERNANDES, 2000).

\section{METODOLOGIA}

Esse estudo de caso é caracterizado por possuir caráter qualitativo, exploratório e explicativo. Apresenta como procedimentos a pesquisa bibliográfica e de campo. A análise do posto de trabalho foi desenvolvida com base na utilização da Análise Ergonômica do Trabalho (AET) a partir da NR-17. Inicialmente foi realizada uma pesquisa bibliográfica, para a construção do referencial teórico, que teve como base artigos, dissertações e literatura técnica sobre AET. Na fase posterior foram realizadas cinco visitas técnicas à fábrica, quando foi possível entrevistar o gerente e a trabalhadora que opera a máquina rebitadeira.

Para a medição das condições ambientais, foi utilizado instrumentação digital. Nessas ocasiões também foram tiradas fotos de todas as etapas do processo produtivo e fotos dos movimentos executados no trabalho, o que proporcionou uma visão abrangente da execução da tarefa, bem como forneceu subsídios 
importantes para as propostas de intervenções.

\section{RESULTADOS E DISCUSSÃO}

A empresa de tipo familiar objeto do estudo, foi fundada em 1993 e atende atualmente toda a Região Norte e Nordeste. O processo produtivo de fabricação das panelas de alumínio inicia-se na etapa de estampagem, quando o operador da máquina de prensa insere e encaixa um disco de alumínio nas dimensões desejadas, de acordo com o tamanho da panela que se pretende fabricar, e aciona a máquina digitalmente. Em seguida, a panela segue para a etapa de desegraxamento que retira os lubrificantes devido a etapa anterior. Esses óleos são removidos através de mergulho das panelas em solução com ácido fosfórico a $85 \%$

Depois de desengraxadas, as panelas seguem para o lixamento, o qual é responsável por dar mais brilho à peça. Depois, as panelas passam por um processo de pintura eletrostática. Para que haja a fixação total da tinta, as peças passam por uma etapa denominada de 'cura', em um forno horizontal com temperatura de $1200^{\circ} \mathrm{C}$. Em seguida, vem a colocação de rebites que prepararão os utensílios para receberem cabos, alças e baquelites que são parafusados posteriormente nas panelas. Os rebites são de alumínio devido ao baixo peso específico, boa resistência à corrosão, atoxicidade, boa condutividade térmica e boa maleabilidade. A figura 1 mostra a etapa de rebitagem das peças. Os rebites são considerados fixadores permanentes, pois ao serem aplicados não é possível reutilizá-los. A figura 2 mostra a sequência das etapas produtivas dando destaque para a operação de rebitagem escolhida para a análise ergonômica.

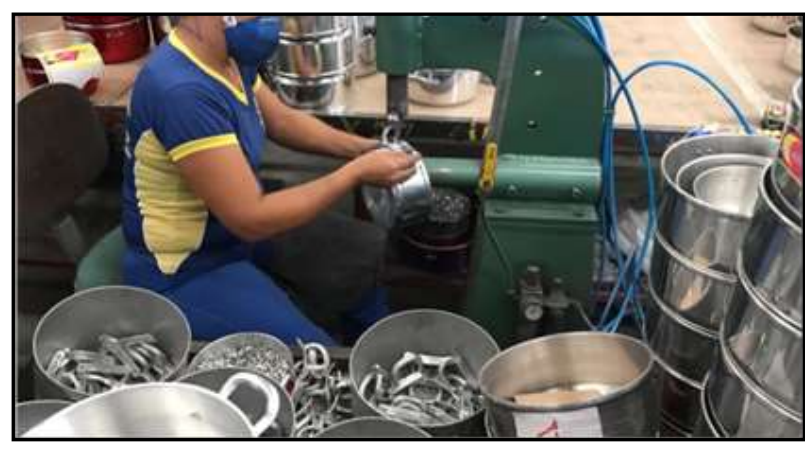

Figura 1: Rebitagem.

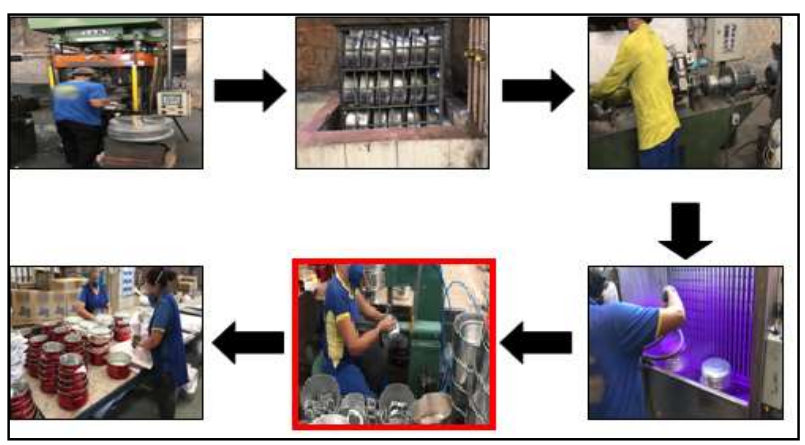

Figura 2: Sequência de Operações

\section{Movimentação de Materiais, Mobiliário e Ferramentas}

Há um funcionário contratado exclusivamente para realizar a movimentação de materiais para o setor de rebitagem, ou seja, este trabalhador realiza a alimentação de panelas a serem rebitadas e posteriormente quando as peças já estão rebitadas, deslocando-as para o setor ao lado referente à parafusação dos cabos e alças. O setor conta com duas mesas, sendo uma mais alta que a outra; e uma cadeira que não é adaptada à fisiologia da operadora (figura 3). As ferramentas utilizadas são: um ajustador de bico para os diferentes tipos de rebites; uma chave allen que serve para apertar ou folgar o bico da máquina; e uma faca adaptada que é utilizada quando o rebite fincado sobre a panela apresenta defeito de fixação (figura 4). 


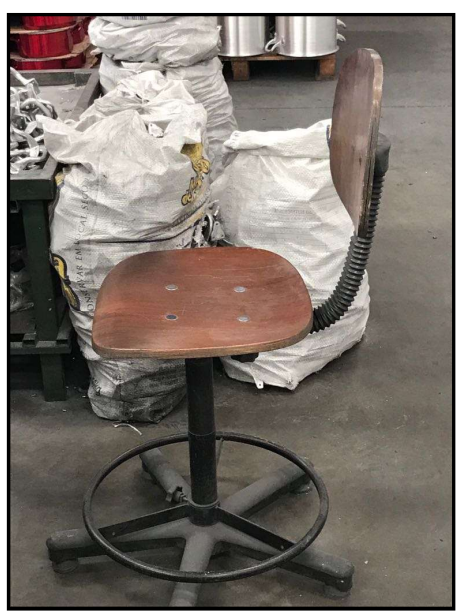

Figura 3: Cadeira.

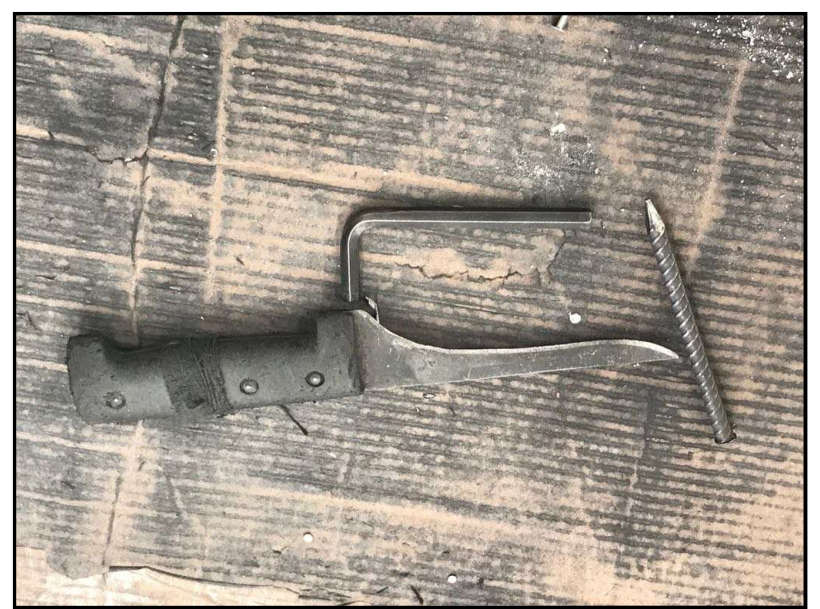

Figura 4: Ferramentas.

\section{Condições Ambientais}

O galpão principal da empresa, que é onde funciona a produção propriamente dita, ocupa uma área de aproximadamente $1800 \mathrm{~m}^{2}$ tendo um pavilhão, com pé direito de $8 \mathrm{~m}$. Na empresa funcionam também os setores administrativos e o refeitório. Existem sanitários na parte lateral, todos no primeiro piso. A área para depósito de matéria prima está localizada numa área de $20 \mathrm{~m}^{2}$ dentro do galpão de produção da fábrica, com facilidade para descarga dos materiais. Existe também uma área de $160 \mathrm{~m}^{2}$, anexa ao prédio principal (ao lado do galpão de produção), destinada ao armazenamento de produtos acabados.

O prédio principal da fábrica, onde se localiza maior parte do setor produtivo, possui cobertura em telhas de fibrocimento alternadas com telhas transparentes para garantir iluminação natural, sendo utilizadas lâmpadas fluorescentes somente em dias nublados e de chuva. Os espaços internos são delimitados pelo próprio maquinário e por matérias-primas e caixas de papelão com os produtos em processamento e acabados. Existe pouco espaço para circulação entre as máquinas, sendo deficiente a delimitação entre setores e corredores.

Em relação à iluminância, foram realizadas medições no posto de trabalho escolhido com o luxímetro, sendo obtido o valor de 97 lux. Conforme a NBR-5413, a iluminância de interiores, desejada na atividade do posto em estudo (rebitagem), é entre 750 e 1500 lux. Portanto, a luminosidade neste posto de trabalho está muito abaixo do recomendado pela ABNT (Associação Brasileira de Normas Técnicas).

Para medição do nível de pressão sonora, foi realizada medição no posto de trabalho de rebitagem próximo ao ouvido da operadora, revelando o valor de $82 \mathrm{~dB}$, o que ultrapassou aos $65 \mathrm{~dB}(\mathrm{~A})$ aceitáveis à finalidade de acordo com a NBR-10152. Deve-se levar em consideração que a trabalhadora utiliza protetor auricular tipo concha com nível de proteção de $14 \mathrm{~dB}$. Portanto ultrapassou em $3 \mathrm{~dB}$ o limite de conforto permitido pela NBR-10152. Em entrevista descobriu-se que a operadora não realiza audiometria regularmente, e ao longo dos treze anos trabalhando nesta empresa só se submeteu ao exame auditivo apenas uma vez.

Observou-se que existem fontes geradoras de calor muito próximo ao setor de rebitagem, a saber, no forno de 'cura' da pintura. As medições mostraram uma temperatura efetiva de $32,4^{\circ} \mathrm{C}$, ou seja, $9,4^{\circ} \mathrm{C}$ a mais que o limite máximo recomendado pela NR-17 item 17.5.2b, mostrando com isso extremo desconforto 
térmico sofrido pela trabalhadora.

\section{Organização do Trabalho}

$\mathrm{Na}$ fábrica estudada, a produção é orientada para grandes quantidades com pouquíssima variação nos produtos, dando ênfase à qualidade e à produção em curto espaço de tempo. Com a preocupação de atender prontamente aos pedidos dos clientes, que geralmente exigem entrega em curto prazo. 0 processo produtivo caracteriza-se por ser do tipo misto (linha e funcional) voltado para o tipo de produção em lote.

Para o posto de trabalho escolhido (operação de rebitagem), a empresa dá preferência à contratação de mulheres alegando que estas são 'mais atentas e cuidadosas'. A operação é realizada com a funcionária sentada e a máquina é acionada com um dos pés. Já houve acidente de trabalho com a máquina de rebitagem na mão direita da trabalhadora, mas segundo o relato do gerente, isso não acontece com frequência e a recuperação foi rápida.

A atividade de rebitagem é monótona e repetitiva. Monótona porque não há estímulo cerebral durante a realização da operação e repetitiva porque pode gerar LER/DORT, pois entre uma rebitagem e outra, a trabalhadora leva em média três segundos. Com base nesta informação, conclui-se que para rebitar uma panela a funcionária leva seis segundos, ou seja, o ritmo é extremamente acelerado. Através de uma entrevista com a funcionária, ficou evidente que ela apresenta LER/DORT pelo relato de que sofre com muitas dores na coluna, nas pernas e nas mãos e que em algumas semanas já ficou afastada do trabalho durante 3 dias seguidos sob atestado médico devido às dores no corpo ocasionadas pelo trabalho.

A jornada de trabalho é de 8 horas diárias de segunda-feira à sexta-feira e de 4 horas aos sábados (portanto, 44 horas semanais). A empresa remunera a trabalhadora da operação de rebitagem, oficialmente, com um salário mínimo, mas a fábrica trabalha com metas diárias (1.100 peças/dia) e a trabalhadora produz mais do que a meta, por isso ela recebe mais de um salário mínimo.

Realizando-se cálculos simples com base na quantidade de peças de meta diária e a velocidade de rebitagem da operária, conclui-se que ela pode produzir um pouco mais que três vezes além da meta, por dia, não havendo, hipoteticamente, nenhuma pausa. Porém, há pequenas pausas, apenas para o uso de sanitário e idas ao bebedouro. Um jogo de panelas (que contém 5 panelas) é vendido no setor de vendas da empresa em média por $\mathrm{R} \$ 50,00$, portanto, de acordo com cálculos simples baseados nestas informações, 10 minutos de um dia de trabalho equivale a seu próprio salário fixo mensal.

No final da jornada diária, a própria funcionária da rebitagem realiza a limpeza do local de trabalho. De acordo com o gerente da empresa, materiais descartáveis, Equipamentos de Proteção Individual (EPIs) como luvas, alguns materiais de limpeza como estopas, além de rebarbas e pó de alumínio são entregues a uma empresa de incineração de resíduos industriais e hospitalares da região do Cariri Cearense, e lá após a incineração eles fazem o descarte do material incinerado de maneira que a agressão ao meio ambiente seja a menor possível. Quanto à água utilizada na etapa de desengraxamento, a própria empresa faz o tratamento da água antes que ela seja lançada em afluentes. 


\section{CONCLUSÕES}

Propõem-se melhorias à fábrica, em específico ao setor de rebitagem, que trarão benefícios à trabalhadora do referido setor, e consequentemente, para todos os funcionários. Tais avanços resolverão os problemas ergonômicos encontrados no serviço de rebitagem. São apresentadas propostas de intervenções: Em relação às condições térmicas: Uma pequena reforma no galpão de produção a fim de deixar as janelas mais aberta, garantindo assim mais entradas de ar natural; e instalação de ventilação e/ou resfriamento evaporativo para serem usados, a ventilação no primeiro semestre do ano e o resfriamento evaporativo, principalmente no segundo semestre do ano, que é um período geralmente quente e seco, característico do clima local.

Quanto à luminosidade, recomenda-se a utilização das lâmpadas fluorescentes LED de 10W das 07h às $09 \mathrm{~h}$ e das $15 \mathrm{~h}$ às $17 \mathrm{~h}$ em dias ensolarados, tendo em vista que há a utilização de iluminação natural através de telhas de fibrocimento transparentes, porém nesses horários a luminosidade é menor; e em toda a jornada de trabalho em dias nublados e chuvosos. Vale salientar que a lâmpada de LED de 10W é econômica e fornece 700 lúmens de fluxo luminoso, o que é suficiente para o conforto lumínico para a atividade estudada, especialmente porque a operação de rebitagem exige acuidade visual e atenção constante.

No que tange ao mobiliário e ferramentas, a empresa deve adquirir uma cadeira adaptada e confortável (de acordo com a NR-17 item 17.3.1). Para a boa e segura utilização das ferramentas, a operadora deve continuar usando todos os EPIs (luvas, máscaras etc.). Quanto ao intenso ruído, a empresa deve adotar a solução clássica de controle com uso de clausuras totais para a redução do ruído. Além disto, a funcionária deve continuar utilizando o protetor auricular.

\section{REFERÊNCIAS}

BACKABERG, S.; RASK, M.; BRUNT, D.; GUMMESSON, C.. Impact of musculoskeletal symptoms on general physical activity during nursing education. Nurse Education in Practice, v.14, n.4, p.385-390, 2014.

BELLO, C. L.; FEITOSA, K. A. C.; GUIMARÃES, L. H.; PANCERI, M.; VERGARA, L. G. L.. Análise ergonômica do trabalho no setor de pet shop: banho e tosa. Recife: ENAEC, 2016.

BLYTH, F. M.; MARCH, L. M.; BRNABIC, A. J.; JORM, L. R.; WILLIAMSON, M.; COUSINS, M. J.. Chronic pain in Australia: a prevalence study. Pain, v.89, n.2, p.127-134, 2001.

CDL. Câmara de Dirigentes Lojistas. Mercado brasileiro de utensílios domésticos deve crescer $\mathbf{3 0 , 8 \%}$. Palhoça: CDL, 2016.

DANIELLOU, F.; BEGUIN, P.. Metodologia da ação ergonômica: abordagens do trabalho real. In: FALZON, P.. Ergonomia. São Paulo: Edgard Blücher, 2007.

FERNANDES, S. C.. Tecnologia e treinamento no aparecimento de lesões por esforço repetitivo: o caso do NPD da UFSC. Dissertação (Mestrado em Engenharia de Produção) - Universidade Federal de Santa Catarina, Florianópolis, 2000.
FIEC. Federação das Indústrias do Estado do Ceará. SIMEC empossa nova diretoria com desafio de aumentar competitividade do setor por meio da inovação. Fortaleza: FIEC, 2015.

GRANDJEAN, E.. Manual de Ergonomia: adaptando o trabalho ao homem. Porto Alegre: Artes Médicas, 1998.

GUARES, S. A.. Gestão de ergonomia e segurança do trabalho: estudo de caso em uma empresa de manufatura de utensílios domésticos em alumínio. Monografia (Graduação em Engenharia Mecânica) - Universidade Tecnológica Federal do Paraná, Pato Branco, 2016.

IIDA, I.. Ergonomia: projeto e produção. São Paulo: Edgard Blücher, 1990.

JELLAD, A.; LAJILI, H.; BOUDOKHANE, S.; MIGAOU, H.; MAATALLAH, S.; FRIH, Z. B. S.. Musculoskeletal disorders among tunisian hospital staff: prevalence and risk factors. The Egyptian Rheumatologist, v.35, n.2, p.59-63, 2013.

LONG, M. H.; JOHNSTON, V.; BOGOSSIAN, F.. Work-related upper quadrant musculoskeletal disorders in midwives, nurses and physicians: A systematic review of risk factors and functional consequences. Applied Ergonomics, v.43, n.3, p.455-467, 2012. 
MARTINS, A. C.. Sintomas osteomusculares relacionados ao trabalho de enfermagem em unidade de terapia intensiva. Dissertação (Mestrado em Enfermagem) - Universidade de São Paulo, São Paulo, 2011.

MERLO, A. R. C.; VAZ, M. A.; SPODE, C. B.; ELBERN, J. L. G.; KARKOW, A. R. M.; VIEIRA, P. R. B.. Trabalho entre prazer, sofrimento e adoecimento: a realidade dos portadores de lesões por esforços repetitivos. Psicologia \& Sociedade, v.15, n.1, p.117-136, 2003

MUGGLETON, J. M.; ALLEN, R.; CHAPPELL, P. H.. Hand and arm injuries associated with repetitive manual work in industry: a review of disorders, risk factors and preventive measures. Ergonomics, v.42, n.5, p.714-39, 1999.

PAULA, A.; HAIDUKE, I. F.; MARQUES, I. A. A.. Ergonomia e gestão: complementaridade para a redução dos afastamentos e do stress, visando melhoria da qualidade de vida do trabalhador. Conbrad, Maringá, v.1, n.1, p.121-136, 2016.
PEDROSA, I. O.; SOBRAL, I. P. A.; BRASILEIRO, M. E.. A atuação do enfermeiro do trabalho na prevenção de riscos ergonômicos. São Paulo: Recien, v.6, n.18, p.3-11, 2016.

PICOLOTO, D.; SILVEIRA, E.. Prevalência de sintomas osteomusculares e fatores associados em trabalhadores de uma indústria metalúrgica em Canoas - RS. Ciência \& Saúde Coletiva, v.13, n.2, p.507-516, 2008.

SANTOS, E.. Polo de alumínio em Juazeiro é o primeiro do Nordeste. Juazeiro do Norte: Diário do Nordeste, 2016.

SIMEC. Sistema Integrado de Monitoramento Execução e Controle. A ascensão do alumínio. Juazeiro do Norte: SIMEC, 2017.

WISNER, A.. Questões Epistemológicas em Ergonomia e em Análise do Trabalho. In: DANIELLOU, F.. A ergonomia em Busca de seus princípios: debates epistemológicos. São Paulo: Edgard Blücher, 2004. p.29-55. 